\title{
$\mathrm{PH} 1044_{\text {reseñas }}$
}

Valero Matas, J.A.

\section{Patrimonio cultural, sostenibilidad y desarrollo humano en lo rural}

Valencia: Tirant Lo Blanch, 2021

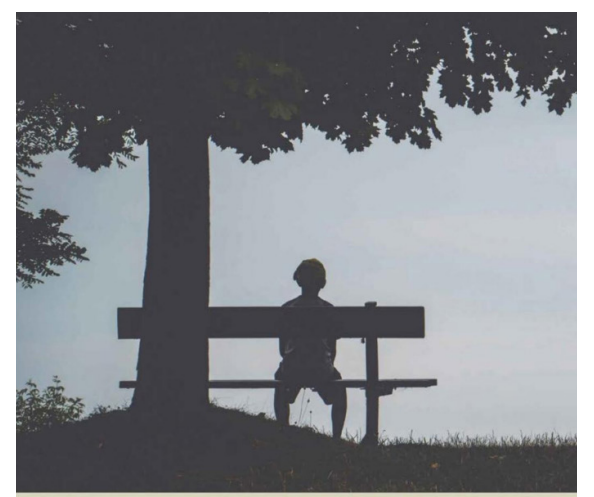

Patrimonio cultural, sostenibilidad y desarrollo humano en lo rural Director:
Jesús Aiberto Valero Matas
Coordindodores: Jose Antonio o 0 rejas Casa
Jesis ortego osa lesis Ortego osa.
Universidida de valtadolid
Se trata de un libro que brinda una mirada multidisciplinar a través de una serie de textos para el análisis y la reflexión del patrimonio cultural en sus diversas dimensiones, para su valoración, para repensar las posibilidades de un nuevo modelo que dinamice espacios rurales con un humanismo sostenible. La obra se organiza en once capítulos, con un prólogo que destaca el esfuerzo conjunto de académicos e instituciones en comunicar sobre el despoblamiento y las políticas de territorialidad para emprender soluciones al abandono rural.

El primer capítulo presenta la labor de las fundaciones, su devenir acercándose al mundo empresarial. Se centra en la Fundación Santa María la Real del Patrimonio Histórico como modelo innovador, sostenible, ético y de buen gobierno. En el segundo se destaca rol de las ciudades intermedias, los cambios que generan en la geografía urbana, abriendo debate para proyectarlas como alternativa o complemento, como conexión entre las grandes ciudades y lo rural.

P.?

En el capítulo número tres, a través de un proyecto de investigación, se muestra la perspectiva museográfica de la cultura tradicional, para reflexionar sobre la representación de la cultura, el proceso de visibilizar y exponer el patrimonio cultural. Precisamente el capítulo que le sigue está referido al análisis del turismo rural, su evolución, características, etc., delimitando el trabajo a la Serranía Celtibérica, para vislumbrar oportunidades del turismo regenerativo contra la despoblación.

El siguiente capítulo enfatiza la necesidad de identificar y revisar dimensiones e indicadores de sostenibilidad de las ciudades, centrándose en la importancia de la gobernabilidad como factor clave para establecer acuerdos, fomentar la humanidad frente a la tecnología y la gestión de los espacios urbanos y rurales. El sexto capítulo, a través de un trabajo comparativo de tres valles pirenaicos en Aragón, analiza el medio físico, eventos históricos, demografía y economía de las últimas décadas, evaluando impactos y perspectivas de desarrollo turístico.

En el capítulo 7, ante la despoblación que considera la España "vacía" como referencia descriptiva y la España "vaciada" resultante de errores y omisiones de políticas públicas, se contrapone el papel de la cultura en el medio rural, presentando iniciativas como activadoras patrimoniales sostenibles. 
El octavo remite al surgimiento de la despoblación rural, procesos, desequilibrios y desigualdades territoriales, la densidad poblacional, dispersión y envejecimiento; la inmigración como tendencia laboral, opción de repoblación y recuperación demográfica. La visión realista de la sostenibilidad y complejidad que resulta de que los inmigrantes puedan poblar municipios rurales, la reflexión para toma de medidas y mantenimiento de espacios rurales viables.

El noveno incide en el reto demográfico y la despoblación. Superar la fase de desierto demográfico, mantener la vida de los pueblos, articular medio rural y medio urbano, realizar acciones y planes que repercutan en la natalidad. Así, ante el presente con la COVID-19, la grave crisis económica, la incidencia en los jóvenes como el colectivo más afectado, con proyectos de vida retrasados, un mercado de trabajo precarizado y opciones de empleo reducidas; la natalidad se afectará negativamente. Se plantea la hipótesis de oportunidad para el medio rural, ofreciendo mejores opciones de vida para enfrentar confinamientos, requiere de cambios globales que deben estructurarse, pero que aún no serán visibles a corto plazo. En el capítulo décimo encontramos una propuesta de interpretación de los usos simbólicos dados a ciertos objetos ganaderos y sus posibilidades expositivas. El significado y sentido metafórico crea nuevas analogías, como crítica a museografía etnográfica que genera exposiciones clasificadas por su funcionalidad práctica.

El undécimo identifica temas relevantes y prioritarios. Ofrece una muestra representativa de ciudades intermedias, defiende su contribución a la toma de decisiones, su adaptabilidad a características específicas. Asimismo, realiza el análisis comparativo de tres iniciativas de ciudades para entender y atender prioridades de las urbes, definiendo índices de ciudades creativas, caminables, competitivas, un análisis cuantitativo que puede dar pautas de las tendencias que se abren paso.

Finalmente, reconocer una publicación poliédrica, amplia y diversa, que permite e invitar a descubrir y reflexionar en torno al patrimonio cultural, la sostenibilidad y la contribución al desarrollo humano en el medio rural.

Silvia Isabel Quinto Fernández | Universidad Nacional de Ingeniería

URL de la contribución <www.iaph.es/revistaph/index.php/revistaph/article/view/4978> 